\title{
The affects of not reading: Hating characters, being bored, feeling stupid
}

Arts \& Humanities in Higher Education 2016, Vol. 15(2) 231-247

(C) The Author(s) 2014

Reprints and permissions: sagepub.co.uk/journalsPermissions.nav DOI: $10.1177 / 1474022214556898$ ahh.sagepub.com

\section{Anna Poletti}

Monash University, Australia

\section{Judith Seaboyer}

University of Queensland, Australia

\section{Rosanne Kennedy}

Australian National University, Australia

\section{Tully Barnett}

Flinders University, Australia

\section{Kate Douglas}

Flinders University, Australia

\begin{abstract}
This article brings recent debates in literary studies regarding the practice of close reading into conversation with Derek Attridge's idea of 'readerly hospitality' (2004) to diagnose the problem of students in undergraduate literary studies programme not completing set reading. We argue that the method of close reading depends on encouraging students to foster positive affective responses towards difficulty - semiotic, emotional and intellectual. Drawing on trials of teaching methods in literary studies' classrooms in four universities in Australia, we suggest that introducing students to the concept of 'readerly hospitality' - rather than assuming an appreciation of difficulty can better prepare students for the encounters they will have in set literary texts and strengthen the effectiveness of classroom teaching.
\end{abstract}

\section{Keywords}

Affect, hospitality, pedagogy, reading, resilience

\section{Corresponding author:}

Anna Poletti, School of Languages, Literatures, Cultures and Linguistics, Faculty of Arts, Monash University, Clayton, Victoria 3800, Australia.

Email: anna.poletti@monash.edu 
Any teacher of literature, from a graduate student on a contract to a professor with decades of experience, has experienced tutorial or workshop discussions that are severely limited because students have not completed the set literary text. In the tearoom after class, over coffee, perhaps even on Facebook, we complain about these classes to each other informally. We develop ad hoc pedagogical strategies, though we know these are no better than coping mechanisms. We replace long texts with shorter ones - teaching Hard Times where once we might have taught Bleak House, 'The Dead' instead of A Portrait of An Artist as A Young Man, On Chesil Beach instead of Atonement. We teach the extracts provided in the Norton Anthology in place of the full text of Paradise Lost or The Origin of Species. We photocopy a few pages and make the students read them in class in order to facilitate a close reading, in the full knowledge that those pages may be the only experience some students have of that particular text. We model good reading practices in our lectures and tutorials, or in online resources (Adlington and Wright: 2012; Culler, 2010: 23). We try to lead by example, and hope we are inspiring enough to be emulated.

In the development of these ad hoc coping strategies we may also engage in some theorizing: we hypothesize that screens are killing attention spans, that Harry Potter has produced a generation of readers focused solely on plot and likeable characters, that the financial constraints of contemporary student life make allocating time for reading more and more difficult. Like Stephen Tabachnik, we may conclude that students are increasingly skilled in visual literacy, but 'display less and less patience with [non-visual] texts, especially long ones' (Tabachnik, 2007: 26). Generally, we know something is not working, and that in the contemporary literary studies classroom we wage a losing battle against the forces - both known and unknown - that result in students submitting plot summaries (probably skimmed from Wikipedia or Sparknotes), and tutorial discussions being held together by the minority who have read the set text. These general observations about reading are drawn both from the published literature on student reading, from our own experiences as teachers of literature, and primarily, from a teaching and learning project we conducted over two years, during which we conducted focus group interviews with teachers of literature, and with staff from teaching and learning centres. We have developed a Reading Resilience Toolkit, in which we provide a range of hands-on examples for implementing a pedagogy aimed at developing reading resilience. ${ }^{1}$ Our aim in this article, however, is to consider the affective components of reading as a core activity of literary studies teaching and research, and to consider how affect shapes students' experiences of reading, the teachers' expectations and responses to students, and the classroom environment itself.

Taking an approach informed by affect theory, in this article we ask not what reading means but what reading can $d o$ - in the classroom and in students' lives. We argue that recognizing and theorizing the variety of affects associated with reading in the literary studies classroom, and the attachments that teachers themselves have to their students' reading and the methodology of reading, adds a crucial dimension to 
debates about 'the way we read now' as a discipline. ${ }^{2}$ These investments in reading are affective as much as they are intellectual. We agree with Chick et al. that effective teaching of literary studies depends on teachers better articulating the intellectual values associated with certain kinds of reading that inform our teaching (2009: 401). Yet our intellectual investment in attentive or close reading as a method for producing knowledge is also an affective one. As Chick et al. discuss teachers of literary studies are invested in teaching affect because they wish to convince students of 'the pleasures of difficulty, complexity, paradox, ambiguity, and the multilayered meanings in literary texts' (2009: 401, emphasis added). ${ }^{3}$ Close reading then is a site of affect - a site we as professionals associate with specific kinds of pleasure, as well as being tied to our identity as professionals (Hayles, 2010: 63-65). But perhaps this emphasis on how an encounter with complexity, ambiguity and paradox should feel (i.e. pleasurable) points to a problem we have in the teaching of literature by reminding us of the connotations of 'discipline' as a synonym for a field of study. We seek to train our students in appropriate means of producing knowledge, making claims about the texts they encounter and what those texts might tell us about the world. Do we also seek to train students in how to feel about the texts and the work they do? If we insist on the methodology also being pleasurable, do we seek to train, or retrain, our students' intuition, if by intuition we mean, following Lauren Berlant, 'where affect meets history, in all of its chaos, normative ideology, and embodied practices of discipline and invention' (2011: 52)?

We address these questions by treating reading as a skill or craft, rather than as a methodology. This approach enables us both to distinguish it clearly from the act of interpretation (hermeneutics) and to focus attention on the fact that whether surface, close, suspicious, reparative, or distant, all reading requires attention and resilience. By thinking of reading as an act of hospitality, following Derrida and Dufourmantelle (2000) and Attridge (2004), and by drawing on recent insights into the role of affect in cultural practices and the production of meaning, we hope to further consider the problem of teaching appreciation for complexity (Chick et al., 2009). We also hope to contribute to debates regarding the role of reading in the discipline, by turning attention to the relational and affective nature of reading in literary studies pedagogy. We approach reading as an encounter between reader and text that requires the reader to be flexible, confident, patient, and open, but that does not stipulate how a given act of hospitality should feel. But first, we outline the current debates about reading as a methodology in literary studies, and the hitherto disconnected discussion of the question of how to teach it.

\section{The return to reading}

Recently, leading scholars have returned to and debated the role of reading as the core practice of the field and, in particular, reconsidered the value of close reading as the primary method for producing knowledge about literature (Best and Marcus, 2009; Culler, 2010; Felski, 2008; Lentricchia and DuBois, 2003; Love, 2010; Miller, 2002; Wedd, 2012). Approaches to reading embedded in critical 
frameworks of the 1970s and 1980s are deemed suspicious or symptomatic concerned with probing the text for its repressed truths (Felski, 2008). In response, a range of new methods have been proposed such as distant reading, where large data sets replace the close attention to a single text (Moretti, 2005); reparative reading that puts aside the practices of mastery traditionally associated with criticism (Sedgwick, 2002); surface reading, where materiality, poetics, and literal meaning are the focus (Best and Marcus, 2009); and descriptive or flat reading, that focuses on the documentary power of literature rather than its potential to situate readers as witnesses (Love, 2010). While close reading is considered the primary skill of someone trained in literary studies - N Katherine Hayles refers to it as 'the sacred icon of literary studies' (2010: 63) - there is no agreed-upon definition. While some argue that the methodology commonly termed close reading is an 'elitist, sacerdotal' hermeneutic that distances twenty-first-century students from the text and as such is best consigned to its New Critical moment in the midtwentieth century (Bialotosky, 2002: 113), there remains a commitment to the importance of what New Critic John Crowe Ransom termed an 'acute' and 'patient' practice as a primary tool for the production of knowledge in the field (1941: x). It is safe to say, as Jonathan Culler does, that the tradition of close reading and attention to a text's 'symptoms' 'inherited from Anglo-American New Criticism' has been carried over into succeeding practices such as deconstruction, psychoanalytic, feminist, postcolonial and queer criticism (2010: 20).

Close reading as a method has become contentious in our contemporary saturated media culture because the discipline of literary studies has been expanding its purview of texts beyond the book (Best and Marcus, 2009: 1). Perhaps more pressingly, however, the cultural practice of reading and cognitive ability to read are being reorganised by the explosion of information made available online (Hayles, 2010). Yet as early as 1986, Barbara Johnson argued that literary studies distinguishes itself from 'speed-reading culture' through its commitment to attentiveness (1986: 140). In her influential essay 'Teaching Deconstructively' she lists 'the kinds of signifying conflicts or tensions that students should look for' and describes a practice that includes 'how to notice things in a text that a speed-reading culture is trained to disregard, overcome, edit out, or explain away; how to read what the language is doing, not guess what the author was thinking; how to take in evidence from a page, not seek a reality to substitute for it' (Johnson, 1986: 140).

While the question of close reading as a basic skill and defining method of literary studies has been reignited, there is also increasing attention given to how close reading can be fostered and taught to undergraduate and graduate students (Adlington and Wright, 2012; Allen, 2012; Chick et al., 2009). Largely eschewing the debate about the value of different styles of reading to the discipline, these studies focus on the pragmatic issue of how to effectively teach, assess and support students in the development of critical or close reading skills. The pressures on higher education teaching - increased class sizes, the introduction of virtual and digital technologies into pedagogy, changing student cohorts, the perceived changing place of the Humanities, a perceived erosion of reading in the primary and 
secondary school curriculum - have led many teachers of literature to re-examine the recent history of teaching close reading by example (Culler, 2010: 23). While some of the theorists engaged in reassessing close reading as the defining method of literary studies have indicated how these debates relate to discipline identity and pedagogy (Hayles, 2010: 63-65) and note the lack of textbooks that can explain different approaches to how to read (Culler, 2010: 22) there has, to date, been little crossover between the applied pedagogical research and the discussion of methodology.

We propose to bring these two current fields of debate and research into conversation by considering the affective dimensions of reading in and for the classroom. While engaged in applied pedagogical research on the question of teaching reading skills to undergraduate literary studies students in Australia, we have become interested in the role that affect plays in teaching and in student engagement with the task of completing reading. We agree with Lauren Berlant's observation that the idiom of affect theory can

provide a way to assess the disciplines of normativity in relation to the disorganized and disorganizing processes of labor, longing, memory, fantasy, grief, acting out, and sheer psychic creativity through which people constantly (consciously, unconsciously, dynamically) renegotiate the terms of reciprocity that contour their social situation.

(Berlant, 2011: 53)

From this perspective, we now consider how the feelings that come with teaching and the expectations of mandatory reading create affect that shape the atmosphere in the classroom, and may help or hinder students' ability to acquire the skills required to be attentive and responsive readers.

\section{The affects of not reading}

All literary studies' subjects require students to complete a certain amount of set, or mandatory, reading. This primary activity - which many of us consider the necessary condition for everything we attempt to do in our teaching - is the source of a great deal of anxiety, disappointment, and shame for both students and teachers. It can also be the source of the most positive intellectual and affective moments in teaching and learning - delight, surprise, seeing parts of the world in a different or new way, a feeling of communion with others or of 'feeling general', perhaps even 'ahistorical' (Berlant, 2008: 1-20). As an expectation, a practice, a requirement, reading has a significant affective charge in the teaching of literary studies. This charge has the potential either to enhance or derail the goals we set for ourselves and the students in our classrooms. Given this potential, we aim to promote discussion in the profession that acknowledges the affective component of reading for both teachers and students, and the development of teaching strategies that can resource students so they are able to recognize and address the power of negative affective responses to texts, and complete set reading in spite of those responses. 
While positive affect can fuel reading, negative affect can prevent it. The goal of our project is, in other words, to turn resistant readers into resilient readers.

During workshops with literature teachers, we noticed that many teachers including us - are attached to an ideal student: the student who completes all set reading prior to class, who undertakes independent research without prompting, and who is open to the distinct pleasures and challenges of reading literature from a range of historical periods and cultures. Each of us may encounter - with varying degrees of regularity - an actual student who approximates this fantasy. However, the source of a lot of negative affect around reading experienced by teachers is our continued attachment to a fantasy of the ideal student (and the resulting ideal teaching moment) in the face of continued disappointment stemming from the failure of a room full of students to meet that ideal. Teaching directed towards the fantasy of an ideal student also produces an experience of cruel optimism: the teacher optimistically hopes that students will do the reading, but is repeatedly met with disappointment (Berlant, 2011). A key reason for this may be that the activity of completing set reading exists outside the classroom and is largely invisible in day-to-day teaching, and in current approaches to literary studies pedagogy.

\section{The invisibility of reading}

Despite renewed interest in reading methodologies, there is only a small, and relatively recent, attempt to explore student reading practices, such as recent studies by Allen (2012), Chick et al. (2009), Jolliffe and Harl (2008) and Manarin (2012). Robert Scholes contends that the decline in reading skills in literary studies has slipped under the radar. While teachers 'normally acknowledge...that writing must...continue to be taught from high school to university and perhaps beyond... we do not see reading' (2002: 166). He further asserts that 'if we could see it, we would be appalled' (2002: 166). Certainly, anecdotal evidence shows that departments and universities put considerable time into resourcing students to achieve the expected standards of academic writing. Reading (as distinct from note-taking), however, is rarely the focus of these programmes. In literary studies subjects, we largely assume that reading happens rather as breathing happens, and focus our energies on teaching interpretation - the act of producing (often writing) a response to a particular narrative in light of specific theories and approaches. One reason for this might be that teaching reading - beyond basic literacy - seems somehow unnecessary. As J Hillis Miller suggests in his discussion of teaching reading as a 'mug's game': 'If you can read, you can read. Who needs any more help?' (2002: 115).

Our research works from the assumption that literary studies does teach the skill of reading. However, at present, whether or not students acquire this skill is largely accidental because, as Scholes argues, we are often more focused on whether or not students can describe their reading in their writing, in the creation of a new text, not whether or not they have actually read the text they are responding to (Scholes, 2002). In our project, we have used the term 'reading resilience' to describe the 
enhanced reading skills students develop through undertaking literary studies. We argue that reading resilience - the skill of reading complex aesthetic and rhetorical texts with patience, perseverance, understanding and appreciation - remains a core skill for success in literary studies, and in the Humanities more broadly, and that the importance of this skill can be communicated to students through course materials and assessment strategies (Kennedy et al., 2013a). For example, in a subject designed to build reading resilience, early lectures and tutorials include dedicated discussion of the skill of reading, making the practices, expectations, benefits and responsibilities of reading transparent. Aligned set 'readings on reading' encourage students to reflect on the science and culture of reading, and are followed up with practical conversations about reading and its place in students' learning. ${ }^{4}$ This can include asking students to reflect on how long it might take to read particular texts and what practical strategies they can employ to ensure they complete the assigned reading on time. We also advocate considering how curriculum design can support reading skills, by rethinking how reading and writing tasks align within the assessment, which we discuss further below. These approaches are aimed at making the invisible labor and skills of reading visible to students.

Our project consisted of two years of developing and trialling ways of foregrounding, in a structured way, the act of reading in order to encourage students to be mindful of the process of reading and of the contract entered into between the reader and the writer when they take up a set text. Thus, like Scholes, we view reading as a craft that can be taught and that consists of the skilful use of certain tools (2001: xiv). Mastering this skill precedes and supports the act of presenting an interpretation, where students produce knowledge about a given piece of literature.

One benefit of explicitly addressing reading resilience as a skill that our teaching seeks to develop is that it enables the negative affect around set reading to be addressed and re-described. Negative (and positive) affects often determine the reading experience, but appear to have no place in 'correct' modes of literary analysis and discussion. For example, we often encourage students to move beyond their feelings of frustration, boredom, arousal, pleasure, anxiety, joy, wonder or stupidity in the teaching environment or in written work. How might this encouragement work to build on, rather than negate, affective responses? One of our team members deploys an interactive oral classroom activity designed to acknowledge affective and personal responses to texts while encouraging the class to physicalize the process of formulating an intellectual response. Students are asked a progressive series of questions about the set text and to locate themselves physically in designated 'yes', 'no' and 'undecided' corners of the classroom. In moving through the questions and answers, their physical movement symbolizes an intellectual pathway and progression through different levels of interpretation. The activity might start by inviting students to express a simple 'gut' response to a text, but the questions become more nuanced and emphasises the need for more attentive, engaged responses. This is not to say that students are guided towards 'better' responses - quite the contrary. The students are asked to consider the relationship between the critiques that they are inclined or able to 
make, and to progress through these as they are exposed to the interpretations of others. This activity also rewards preparation: where the initial questions might allow for general responses that students can draw from their memory of the text, the latter questions require the students to utilise their notes and their copy of the text. By demonstrating to students that reading attentively and in detail is a central skill for acquiring competency in literary studies, we can create an environment where affective responses can be incorporated into the teaching process rather than being an unnamed force that works against it. As we discuss below, this approach requires that we think of the classroom as an assemblage made up of elements that are intentionally brought to the scene of learning as well as those that are contextual, accidental and serendipitous.

In describing the problem of reading in these terms we are approaching the current debates about the methodology of reading from a slightly different angle. As the critiques of Best and Marcus's theory of surface reading have persuasively argued, it is a mistake to back away from the important theoretical and methodological recognition that all reading is productive, "that our "reading" is always also a writing' (Rooney, 2010: 124). It is true that in attempting to disarticulate reading as the primary methodology through which literary studies produce knowledge from specific theoretical traditions Best and Marcus may be accused of attempting to return us to a prelapsarian state before the methodologies practiced under 'objectivity' and 'the text itself' had sustained a level of critique which made them unutterable without qualification, if utterable at all (Rooney, 2010: 123-125 see also Weed, 2012). However, the debate regarding symptomatic and surface reading is informed by feelings about the work we do, just as the applied pedagogical research is informed by feelings about teaching. Rooney indicates the importance of affect to these debates when she insists on the important of Althusser's formulation of reading as 'guilty': 'Foremost amongst [the concepts from Althusser that Best and Marcus overlook] is the claim that reading is 'guilty' and bears the burden of its own problematic, which is to say that it is inevitably productive' (2010: 128). Rooney's critique is that Best and Marcus wish to avoid this guilt - the inevitable guilt of reading - by practicing description and attentiveness, less powerful, more humble activities with (presumably) less affective charge.

Rooney's return to Althusser and the critiques of objectivity remind us that producing knowledge cannot be done without feelings. If Rooney is correct in asserting that 'teaching instantiates the problem of method' (2010: 121), then examining how we feel about what we do, and how our students feel about what we ask them to do, offers an important angle from which to consider current debates about pedagogy, methodology and how the field of inquiry is constituted. If Rooney is right that we must acknowledge the guilt of reading, then what does it mean to train people in an activity that has embedded in it a negative affect that must be acknowledged and cannot be absolved of 'its crime on confessing it' (Althusser quoted in Rooney, 2010: 129)? One potential response is anxiety. 'Why I am doing this with my life? Does it matter? Do I deserve to be doing it? What have I really been teaching? What have I really been learning? Where am I 
going?' these 'fundamental questions of identity and purpose' are, Elaine Showalter argues, 'inherent to the study of literature as well' (2003: 4). If, as Lauren Berlant suggests, anxiety 'is the affective copy of ambivalence, where we work out our conflicting inclinations toward what kind of closeness and distance we want, think we want, and can bear our object to have' (2008: 13), then we might also recognise that anxiety about teaching is a component of our attachment to the discipline. More specifically, our current collective anxiety about the state of reading as method and practice is a component of our investment in the discipline, disciplinary identity and our role as teachers. This draws our attention to the classroom as an affective space.

\section{Teaching, learning and affect}

Considering education as an affective space enables educators to see the non-cognitive processes that influence a student's ability to respond cognitively to the requirements of the class. Megan Watkins writes that 'learning is generally conceived as a cognitive activity. While it has an affective dimension this seems to receive very little theoretical explication' (2006: 279-280). How affect might develop in a student and how it functions in an equation involving students and literature require more attention.

The concept of assemblage, which has been articulated by Deleuze and Guattari and taken up by a range of theorists, is useful for conceptualizing the role of affect in teaching and learning. The Oxford English Dictionary defines assemblage as 'a bringing or coming together; a meeting or gathering; the state of being gathered or collected'. As J Macgregor Wise (2005) points out, for Deleuze and Guattari assemblage articulates 'the play of contingency and structure, organization and change'; he points out, however, that 'we should also keep in mind that these pairs of terms are false alternatives' (2005: 77). An assemblage is neither 'predetermined' nor 'random'; rather, it is considered to be 'a whole of some sort that expresses some identity and claims a territory' (Wise, 2005: 77). An assemblage is a collection of heterogeneous elements, but this collection is not random since the elements 'constitute a group and they express a particular character' (Wise, 2005: 78, emphasis in original). An individual university course in literary studies can be usefully thought of as an assemblage made up of personal endeavours (preparation for class by students and teachers), the texts that are the shared resources for discussion, an online site where reading lists and lecture notes are posted, lectures, group meetings in the classroom, the preparation and marking of assessment, study groups, and informal meetings such as consultation or chats about the course while waiting in line for coffee. Some of these components are assemblages in their own right: the classroom can be approached as an assemblage that consists of a collection of heterogeneous elements, including teacher, students, tables, chairs, books, notebooks, computers, mobile phones, iPads, projectors, screens, pens, paper and lights.

The classroom as assemblage is characterized by a contingency in the elements, which typically change from one class meeting to the next: the students may not be 
the same every week, there may be a guest lecturer or tutor, the class may meet in a different room, the desks may be arranged differently, and the computer equipment may not be the same or may not work. More or fewer students may have computers and iPhones, which may ring more or less often. What makes a course an assemblage rather than a random collection of elements is that the elements that form the class clearly 'constitute a group' and 'express a particular character'. The elements that constitute the 'class' are considered to be 'a whole of some sort that expresses some identity and claims a territory'. For example, the class claims a physical territory, and this feature distinguishes it as an assemblage from distance learning, in which the elements do not inhabit a shared physical territory. The course also claims an intellectual territory by being focussed on a specific topic, such as women's writing, Renaissance poetry or memoir. Following Deleuze and Guattari, the important question to ask about an assemblage is not what it is (i.e. its identity and meaning) but what it can $d o$; that is, how it functions. Conceiving of a university course as an assemblage enables us to see how reading as a practice takes place in a context in which bodies - human and non-human, material and immaterial - interact and produce affects and affective relations.

In the assemblage of the literary studies course, the negative affects produced when student reading is not resilient appear in a range of elements: poor reading skills show up in assignments of pass or fail grade quality, classroom discussion is stilted or resistant. We certainly hear our students reporting on their affective responses in tutorials when they tell us that they 'hated' a book or that a given protagonist or narrator is 'annoying'. Students may also confess that they did not finish the book because they could not relate to the central character, the problem the narrative sets up and addresses, or the setting (or all three!). Often we try to reshape these personal responses into interpretation through guiding our students towards better interpretations. However, in doing so we often miss the affective subtext of the student's statement: that they did not feel up to the task of reading the set text. Hating characters, being bored, being made to feel stupid by a text, or feeling that a text is stupid are the common negative affects associated with set reading that students experience in their preparation time and bring with them into the assemblage of the classroom. Resentment can abound because reading literature requires the reader to do more emotional work, to commit to a narrator's or character's or author's world view or agenda in a way that is more intrusive than, say, reading a textbook (see Douglas and Barnett (2014) for an exploration of this through a case study). We argue that acknowledging the presence and influence of affects and their relation is an important part of teaching reading resilience because it enables reflection upon and incorporation of affect into the critical practice that the individual course - and the degree for which students are studying - fosters. It allows students to see the role that reading plays in a complex and interdependent system of learning activities and therefore to give reading a higher priority in their educational activities.

By engaging with our students through the concept of reading resilience, these affects can be understood and consciously incorporated into the assemblage of the 
course by encouraging students to think and talk about reading as an act of hospitality. In the final section, we give some concrete examples of how, informed by attention to feelings that reading may generate, we implement reading resilience in the classroom.

\section{Reading as an act of hospitality}

Derek Attridge, in The Singularity of Literature, argues that any act of reading that goes beyond the most basic mechanical decoding of letters into conceptual structures can be 'an attempt to respond to the otherness, inventiveness, and singularity of the work' which enables an experience of 'readerly hospitality, a readiness to have one's purposes reshaped by the work to which one is responding' (2004: 7980). To achieve this, the reader must be prepared to 'suspend habitual modes of thinking and feeling' (Attridge, 2004: 83). Here Attridge is continuing a longstanding conversation with Derrida and Dufourmantelle (2000), whose work on hospitality foregrounds the uniqueness of the 'law' of hospitality that implies 'not only a willingness to accept the other into one's own domain, but to change that domain, perhaps radically, to make the other welcome' (Attridge, 2004: 152 n.25).

Attridge identifies a linked response to reader/text hospitality that is familiar to us as teachers of literature. This is the kind of reading that refuses the other not by rejecting it but by assimilating it to the same -'I realy identify with Jane Austen's Emma, or Jonathan Franzen's Patty, or Alexis Wright's Oblivia. I know just how she feels.' This familiar response, in refusing the text's otherness, risks reducing literature's complexity to a mirror that simplistically reflects the reader back to themselves. Attridge argues that to do justice to the text in all its inalienable otherness, the reader must bring to it not only the kinds of disciplinary skills and techniques we want our students to acquire, but also the imaginative courage to rethink one's own ethos in order to fight against the mind's tendency 'to assimilate the other to the same'. The hospitable reader attends 'to that which can barely be heard, registering what is unique about the shaping of language, thought and feeling in this particular work. It involves a suspension of habits, a willingness to rethink old positions in order to apprehend the work's inaugural power' (Attridge, 2004: 80; see also 32-33). Reading, he says, involves 'an encounter in which existing modes of thought and evaluation falter, [but] creative reading allows the work to take the mind (understood in the broadest sense) to the borders of its accustomed terrain' (Attridge, 2004: 80). Obviously such an act of hospitality involves danger; our role as educators is to teach the skills that will foster the courage as well as the skills with which to read responsibly, to produce, as Attridge terms it, a response and not just a reaction to a text (2004: 39 and 81).

From the perspective of literary studies pedagogy, this idea of reading as hospitality has the potential to frame our thinking about our expectations of students, but also to explicitly frame for them how and why their encounters with texts are sometimes awkward, difficult or challenging. To encourage our students to think of 
themselves as hosts to the text as guest reminds us, too, of the fundamentally challenging nature of the work we ask our students to undertake - after all, suspending habitual modes of thinking and feeling is not easy - and it empowers the students not to be put off when they encounter challenges in the texts we set. It does this by making reading visible as a process, as a challenge and as a worthwhile pursuit that is not going to happen miraculously before class without the application of intent and effort, without scheduling time and without the physical movement of the body and the mental movement of the mind into a position to be receptive to a deep and sustained engagement. It also empowers students to complete the reading by evoking them as part of a reading community, with other students and staff, and as an important part in the equation of reading. If reading is cast as an active encounter and an exchange with a 'vibrant object', to use Jane Bennett's term, that has something akin to rights, the reluctant student may reconfigure the encounter with the text as something more than an item for consumption (Bennett, 2009).

Thinking of reading as an act of hospitality in the context of literary studies pedagogy, then, we can begin to think about the negative affects experienced by our students that prevent them completing set reading as responses to their requirements as hosts, and as the inevitable moments of difficulty that arise from even the most willing suspension of habitual ways of thinking and feeling. If students are introduced to the reading experience as one that puts them in the position of host rather than guest in the encounter, the reading dynamic may change into one that helps motivate students to complete the reading and face the challenges that stem from it.

\title{
The risk of hospitality: Why we need resilience to read
}

Thinking of reading as an act of hospitality can allow a different perspective on the negative affects reported by students in tutorials or evidenced in essays and exams. Reminding teachers that the tasks we set students involve affects associated with risk forms part of our case for the skill of reading resilience. Hillis Miller suggests all reading is a scene of risk:

\begin{abstract}
A book in my hands or on the shelf utters a powerful command: 'Read me!' To do so is as risky, precarious, or even dangerous as to respond to another person's 'I love you' with 'I love you too'. You never know where saying that might lead you, just as you never know where reading a given book might lead you. (Miller, 2002: 120)
\end{abstract}

However, a preparedness to be led does not, we think, adequately describe the resilience that reading a challenging text requires, nor the activities that will help prepare student for the task. Indeed, while we find Miller's description of reading as being as risky as loving to be compelling, we believe that the act of hospitality that constitutes reading requires more activity than allowing oneself to be taken on a journey. 
The concept of hospitality, conceived of as an encounter with the other, provides a useful model for conceptualising the student's encounter with a 'foreign' text. As Derrida and Dufourmantelle explain in Of Hospitality, 'absolute hospitality' involves not only welcoming into one's home a foreigner who is identifiable as a foreigner, but also the 'absolute, unknown, anonymous other' (2000: 25). In the act of reading, considerable risk attends hospitality as soon as it requires the reader-host to encounter texts that present views different from their own. Tamar Katz observes that students 'want to read every text as saying something extremely familiar that they might agree with' (Katz quoted in Scholes, 2002: 165). In this tendency Robert Scholes identifies two issues: 'One is a failure to focus sharply on the language of the text. The other is a failure to imagine the otherness of the text's author' (2002: 166). In this first failure, we might say that the problem is that the student, as a reader-host, fails to actually see their guest for who they are. They have a pre-existing sense of who they would like to visit them, and treat whoever arrives as that hoped-for guest. Problems arise when students are hoping for the cherished familiarity of a Harry Potter only to be confronted with the radical unfamiliarity of, say, the archaic language and philosophical depth of Middlemarch. In such a case, as well as arguing for the value of persevering with what is widely considered one of the most important novels in the English language, we need to discuss with students the kinds of difficulties they should expect and how they might best approach the task. In our study, we trialled ways of staging this conversation, through a series of aligned activities that encourage the kind of reader engagement and agency that enable openness to the otherness of the text. ${ }^{5}$ This included preparing short reading guides that include prompts and information to support the hospitable encounter by promoting awareness of, for example: the language used and the work it does in terms of meaning making; characterisation; structure; intertextuality; context. We also trialled using summative assessment in order to emphasise the importance of consistent application to the task of hospitality over the course of the semester and to give feedback on students' acquisition of reading skills. We did this by assigning short reading tasks that contributed to the final mark for a course, and were submitted before, during or after class. ${ }^{6}$

Beyond the failure of recognition, there are other risks that come with reading. Hillis Miller, too, recognizes responsible reading to be a risky undertaking, but his warning addresses the negative affect associated with reading as literary critique. If we are 'to read literature rightly' (2002: 120), offering the requisite readerly hospitality, we must read in two ways that not only run counter but actually '[inhibit] and [forbid] the other' way of reading (2002: 124). On the one hand we must read innocently, giving ourselves up to the world of the text, to its enchantment, 'without suspicion, reservation or interrogation,' and on the other we must read suspiciously, 'looking circumspectly before and after, walking rather than dancing, anxious not to let the text put anything over on us' (Miller, 2002: 122). In other words, we must at once appreciate and demystify the magic. Whether such a 
reading is undertaken at a rhetorical level, '[attending] to the linguistic devices by which the magic is wrought,' or whether the reading interrogates, for example, the cultural ideologies the text inculcates, one of the effects of demystification will be to ensure the magic no longer works (Miller, 2002: 122-123). Who can blame the student who is angered by a discipline that celebrates literature's magic only to destroy it?

The final risk attendant on reading as an act of hospitality is the risk of failure. To begin a book is to enter into the possibility that we may not finish it.

Thinking of reading as a scene of hospitality that occurs within the assemblage of a particular literary studies course allows us to recognize that the kind of reading we are asking our students to engage in is a profoundly risky and anxiety-promoting act of hospitality, an act of opening oneself to the text as other, an act of enjoying and demystifying literature. Our role is to find ways of enabling students' reading resilience so that their sense of these risks, or their direct encounters with them, do not result in their giving up reading the texts we set for them. Emphasizing the act of reading as one of hospitality may motivate students to accept the challenge of personal exchange, with its attendant requirements for hospitality to complete the set reading.

\section{Declaration of conflicting interests}

The authors declared no potential conflicts of interest with respect to the research, authorship, and/or publication of this article.

\section{Funding}

The authors received no financial support for the research, authorship, and/or publication of this article.

\section{Notes}

1. Building Reading Resilience: Developing a Skills-Based Approach to Literary Studies (Kennedy et al., 2013a) was funded by the Office of Learning and Teaching (Australia). It seeks to describe and document some of the issues that block students from becoming resilient readers. It also develops a set of practical activities that tertiary teachers of literature can use in the classroom to develop reading resilience.

2. This is a reference to the title of a special issue of Representations edited by Sharon Marcus and Stephen Best in 2009. See Rooney and Weed for responses to the formulation of 'surface reading' proposed in the introduction.

3. Ira James Allen suggests literary studies academics do less of this 'real reading' than we think we do, and this itself leads to negative affect of disappointment (with ourselves) and longing.

4. See the Reading Resilience website (Kennedy et al., 2013b; http://chelt.anu.edu.au/ readingresilience/) on setting Readings on Reading for more information.

5. See our Reading Resilience website (Kennedy et al., 2013b; http://chelt.anu.edu.au/ readingresilience/) for more detailed information.

6. The second failure, the inability to imagine authorial otherness, is perhaps more familiar to many of us. The underlying problem is an unwillingness to engage with 'difference, or 
otherness - a difficulty in moving from the words of the text to some set of intentions [...], some values or presuppositions different from one's own and possibly opposed to them' (Scholes, 2002: 166). Many of us have well-developed pedagogical strategies for introducing students to the concept of the other and its relevance. However, we are perhaps less good at preparing and supporting our students in encountering the other that is the text itself, and thus often discover that many students have avoided the very encounter that is the foundation of the intellectual development we are seeking to encourage.

\section{References}

Adlington $\mathrm{H}$ and Wright G (2012) Teaching close reading: A VLE-based approach. Arts and Humanities in Higher Education 12(1): 1-17.

Allen IJ (2012) Reprivileging reading: The negotiation of uncertainty. Pedagogy: Critical Approaches to Teaching Literature, Language, Composition and Culture 12(1): 97-120.

Attridge D (2004) The Singularity of Literature. London: Routledge.

Bennett J (2009) Vibrant Matter: A Political Ecology of Things. Durham: Duke University Press.

Berlant L (2008) The Female Complaint: The Unfinished Business of Sentimentality in American Culture. Durham, NC: Duke University Press.

Berlant L (2011) Cruel Optimism. Durham, NC: Duke University Press.

Best S and Marcus S (2009) Surface reading: An introduction. Representations 108: 1-21.

Bialotosky D (2002) Should college English be close reading? College English 69(2): 111-116.

Chick NL, Hassel H and Haynie A (2009) 'Pressing an Ear against the Hive': Reading literature for complexity. Pedagogy: Critical Approaches to Teaching Literature, Language, Composition and Culture 9(3): 399-422.

Culler J (2010) The closeness of close reading. ADE 149: 20-25.

Derrida J and Dufourmantelle A (2000) Of Hospitality. Trans. Rachel Bowlby. Stanford: Stanford University Press.

Douglas K and Barnett T (2014) Teaching traumatic life narratives: Affect, witnessing and ethics. Antipodes 28(2): 51-68.

Felski R (2008) Uses of literature. Malden, MA: Blackwell.

Hayles NK (2010) How we read: Close, hyper, machine. ADE 150: 62-79.

Johnson B (1986) Teaching deconstructively. In: Atkins GD and Johnson ML (eds) Writing and Reading Differently: Deconstruction and the Teaching of Composition and Literature. Lawrence: University of Kansas Press, pp.140-148.

Jolliffe DA and Harl A (2008) Studying the 'Reading Transition' from high school to college: What are our students reading and why? College English 70(6): 599-617.

Kennedy R, Douglas K, Poletti A, et al. (2013a) Building Reading Resilience: Developing a Skills-based Approach to Literary Studies. Office for Learning and Teaching, DIICCSRTE, Sydney. The Final Report and the Reading Resilience Toolkit. Available at: http://www.olt.gov.au/resource-library?text=building + reading + resilience (accessed 21 August 2014).

Kennedy R, Douglas K, Poletti A, et al. (2013b) Reading Resilience Toolkit. Available at: http://chelt.anu.edu.au/readingresilience/ (accessed 21 August 2014).

Lentricchia F and DuBois A (2003) Close Reading: The Reader. Durham, NC: Duke University Press. 
Love H (2010) Close but not deep: Literary ethics and the descriptive turn. New Literary History 41(2): 371-391.

Manarin K (2012) Reading value: Student choice in reading strategies. Pedagogy: Critical Approaches to Teaching Literature, Language, Composition and Culture 12(2): 281-297.

Miller JH (2002) On Literature. New York, NY: Routledge.

Moretti F (2005) Graphs, Maps, Trees: Abstract Models for a Literary History. New York, NY: VERSO.

Ransom JC (1941) The New Criticism. Norfolk, CT: New Directions.

Rooney E (2010) Live free or describe: The reading effect and the persistence of form. Differences: A Journal of Feminist Cultural Studies 21(3): 112-139.

Scholes R (2001) The Crafty Reader. New Haven, CT: Yale University Press.

Scholes R (2002) The transition to college reading. Pedagogy: Critical Approaches to Teaching Literature, Language, Composition and Culture 2(2): 165-172.

Sedgwick EK (2002) Paranoid reading and reparative reading, or, you're so paranoid you probably think this essay is about you. Touching Feeling: Affect, Pedagogy, Performativity. Durham, NC: Duke University Press, pp.123-154.

Showalter E (2003) The anxiety of teaching. Teaching Literature. Malden, MA: Blackwell, pp.1-20.

Tabachnik SE (2007) A comic-book world. World Literature Today: A Literary Quarterly of the University of Oklahoma 81(2): 24-28.

Watkins M (2006) Pedagogic affect/effect: Embodying a desire to learn. Pedagogies: An International Journal 1(4): 269-282.

Weed E (2012) The way we read now. History of the Present 2(1): 95-106.

Wise JM (2005) Assemblage. In: Stival CJ (ed.) Gilles Deleuze: Key Concepts. Montreal: McGill-Queens Press, pp.77-87.

\section{Author biographies}

Anna Poletti is a lecturer in Literary Studies at Monash University and director of the Centre for the Book. Her research interests are autobiography, mediation, and life writing in youth cultures. She was a researcher on the recently completed project 'Building Reading Resilience: Developing A Skills-based Approach to Literary Studies' funded by Australia's Office of Learning and Teaching. In 2014, Anna coedited a special issue of Australian Humanities Review on the topic of 'Revealing the Reader' and the essay collection Identity Technologies: Constructing the Self Online (U Wisconsin Press).

Judith Seaboyer is a lecturer in literature at the University of Queensland. As a result of her involvement in the Reading Resilience project that drives this essay, she has become increasingly engaged in pedagogical concerns, particularly as they support better student reading. She is a visiting scholar at Oxford Brookes University (2014-2016) where she is involved in a project on the transformational power of reading, and she has just completed a Learning Innovation Teaching Fellowship at the University of Queensland that looked at online quizzes as a way to improve student reading and engagement. She is presently involved in a 
project to strengthen gateway courses across the University that sets out to improve critical literacy, engagement, and resilience and to foster a sense of community across a dispersed humanities cohort.

Rosanne Kennedy is Associate Professor of Literature and Gender, Sexuality and Culture at the Australian National University. She has held numerous grants and fellowships, including as team leader of a project funded by the Office of Learning and Teaching: 'Building Reading Resilience: Developing a Skills-Based Approach to Literary Studies'. Her postgraduate Thesis Writing Workshop has been nominated for a National ALTC Citation Award. Her research interests include trauma, testimony and memory and its re-mediations in cultural, literary and human rights texts and contexts. Her articles have appeared widely in journals including Memory Studies, Comparative Literature Studies, Biography, Studies in the Novel, Women's Studies Quarterly, Australian Humanities Review and Profession. She recently edited with Susannah Radstone a special issue of Memory Studies on 'Memory Studies in Australia' (July 2013).

Tully Barnett is a Research Fellow in the School of Humanities and Creative Arts at Flinders University, South Australia, with an ARC-funded project investigating cultural value for arts, culture and collecting institutions. She is Research Associate for the Australasian Consortium of Humanities Research Centres and publishes on technologies of reading such as Kindle social highlighting and Google Books. She is the author of 'Social Reading: The Kindle's Social Highlighting Function and Emerging Reading Practices,' Australian Humanities Review (2014). "Reading Saved Me": Transformative Reading Experiences in Life Narrative,' Prose Studies (2013) and 'Remediating the Infected Body: Writing the Viral Self in Melinda Rackham's carrier', Biography special issue on PostHuman Lives (2012).

Kate Douglas is an Associate Professor in the School of Humanities and Creative Arts at Flinders University (South Australia). She teaches in Literary Studies and her scholarship of teaching interests include building students' reading resilience, reading with new technologies, teaching traumatic literatures and literature and 'trigger warnings', and she has published across these subjects. Kate is an Office of Learning and Teaching (OLT) grant recipient and won an OLT National Teaching Citation in 2010 for Outstanding Contribution to Student Learning. She is a member of Flinders University's College of Distinguished Educators. 